\title{
CONTROL LEVEL AND ASSESSMENT OF THE CLINICAL COURSE IN PATIENTS WITH THE ASSOCIATED PATHOLOGY OF BRONCHIAL ASTHMA AND COPD
}

\author{
Yurii Feshchenko \\ Department of pulmonology \\ SO "National institute of phthisiology and pulmonology \\ named after F. G. Yanovskyi NAMS of Ukraine" \\ 10 M. Amosova str., Kyiv, 03141, Ukraine \\ admin@ifp.kiev.ua \\ Ksenia Nazarenko \\ Department of pulmonology \\ SO "National institute of phthisiology and pulmonology \\ named after F. G. Yanovskyi NAMS of Ukraine" \\ 10 M. Amosova str., 03141, Kyiv, Ukraine \\ k.nazarenko123@gmail.com
}

\footnotetext{
Abstract

The notion "asthma-COPD cross" (ACC) for patients with clinical signs of bronchial asthma and COPD was introduced. From 15 to $45 \%$ of population with bronchial obstructive diseases suffer from ACC and its prevalence increases with age.

According to the data of epidemiological studies, in average a half of patients with BA in the world cannot reach a control of BA or keep it for a long time.

The aim of our research was the determination of the control level and also assessment of symptoms of the disease of patients with BA and COPD.

Patients. The study included patients with ACC, older than 30 years. The control included patients with the bronchial asthma and COPD without any signs of these pathologies combination.

Methods. All patients underwent the spirography with the analysis of the curve "flow-volume" of a force exhalation and also bodypletizmography ("MasterScreenPneumo", «CardinalHealth» (Germany)). Al patients were interrogated by the questionnaires: questionnaire for BA symptoms control (ACQ-7), test for BA control (ACT), test for COPD assessment CAT).

Results. At comparing parameters of BA control was revealed the reliably worse control in the group of patients with the associated pathology by data of the questionnaire ACQ-7 comparing with patients with BA. The influence of COPD symptoms was also more essential in patients with ACC comparing with one with COPD.

At the more expressed degree of the bronchial obstruction, BA control was reliably weaker, whereas the influence of COPD symptoms was more essential.

In patients with ACC with the unsatisfactory control of BA (ACQ-7 $\geq 1,5$ points) the mortality prognosis, expressed by BODE index, grows almost in 3 times; inpatients with the severe and very severe influence of the disease effect (CAT $>20$ points), the mortality prognosis grows more than in 2 times.

The reliable positive correlation was revealed between the results of CAT and ratio of the internal thoracic volume of gases to the total capacity of lungs (ITGV/TLC), that reflects the degree of lungs hyperinflation $-(\mathrm{r}=0,35 ; \mathrm{p}<0,05)$.

Conclusions. At BA and COPD combination the indices of the disease control are worse than at the bronchial asthma and a bit similar to ones at COPD.

Indices of BA control and influence of COPD symptoms on the condition of patients with the associated pathology were mainly negatively changed at the increase of the bronchial obstruction degree.

The essential negative influence of the insufficient BA control and the high influence of COPD symptoms on the disease prognosis in patients with associated pathology (BA+COPD) were revealed.
}

Keywords: associated pathology of bronchial asthma and COPD, control of disease, prognosis.

DOI: $10.21303 / 2504-5679.2017 .00393$

(C) Yurii Feshchenko, Ksenia Nazarenko

\section{Introduction}

In the world near 1 of 12 persons suffers from the bronchial asthma (BA) or COPD, and if earlier these two nosologies were considered as two different diseases, for today it is generally 
accepted, that they are heterogenic and often crossed. The notion "asthma-COPD cross" (ACC) for patients with clinical signs of the bronchial asthma and COPD was introduced. From 15 to $45 \%$ of population with bronchial obstructive diseases suffer from ACC and its prevalence increases with age $[1,2]$.

According to the data of epidemiological studies, in average a half of patients with BA in the world cannot reach a control of BA or keep it for a long time.

In studies are demonstrated essential losses of the health protection system, connected with the persisting BA [3]. Also in literature are presented data about the close connection of the disease control with the life prognosis in future [4]. In separate works the bad BA was associated not only with the worse prognosis but also with the patients' life quality decrease [5,6]. It is also not a surprise that the insufficient BA control is an essential medical-social problem.

The complicacy and difficultness of the asthma control assessment as an integral parameter under conditions of the real practice cause the necessity of introducing and using adequate and effective instruments.

For today in clinical studies and everyday practice well proved clinical instruments for the symptoms assessment are used: asthma control test (ACT) and asthma control questionnaire (ACQ), that allows to estimate the condition of asthma control in points using the easy but objective method, in a short period of time taking into account most important symptoms. These tests are reliable instruments of the monitoring of the condition of patients with BA, and treatment effectiveness assessment.

$\mathrm{BA}$ control test (ACT) is the questionnaire, easy for the use and calculation, which data by the results of examinations well correlate with doctors' assessment by the data of the disease anamnesis, physical examination and measuring of the external breath function, and also with ACQ results $[7,8]$.

ACT includes 5 questions, connected with symptoms, frequency of using bronchodilators of a short-term action, and self-assessment of the BA control level. The scale of points from 1 to 5 is offered for answers. At summarizing points the result $\leq 19$ indicates an uncontrolled BA, 20 and more points - a controlled clinical course.

ACQ is a reliable instrument that allows to estimate the BA control exactly and with reproduction [10]. The data of independent studies give proofs about validity of the questionnaire for BA control, and the possibility of its use in the general practice and for clinical studies $[11,12]$. The questionnaire includes questions about BA symptoms, use of bronchodilators with a short-term action (ACQ-6), and also the volume of a forced exhalation for 1 second (FEV1) (ACQ-7) [13]. Results of answers to 6 or 7 questions (depending on a possibility to study the external breath function $(\mathrm{EBF}))$ are averaged for receiving the final index. For determining the control level, 2 threshold values were described. The mark $\leq 0,75$ points means that BA is controlled, and the value $\geq 1,5-$ uncontrolled [11]. The interval from 0,75 to 1,5 - so-called "grey zone", from our point of view, it may be assessed as a partial control of asthma.

For estimating COPD symptoms, COPD assessment test (CAT) is offered. It allows to estimate an influence, caused by the disease on patients' health condition and life quality [14, 15]. The test includes 8 items, which answers vary from 0 - no problem, to 5 - maximally expressed problem. The questions reflect different aspects of the health condition worsening at COPD. The general sum of points may be from 0 (the best index) to 40 (the worst index); closely correlates with the health status, measured according to the questionnaire of St. George hospital [16]. CAT points $0-10,11-20,21-30$ and 31-40 represent, light, moderate, severe or very severe clinical course of the disease.

For today the disease control assessment and clinical factors, conditioned by BA+COPD association, are insufficiently studied.

\section{Aim of research}

The control determination and symptoms assessment of patients with BA and COPD association, who undergo the usual basic therapy according to the disease severity degree. 


\section{Materials and methods}

The study included patients with signs of both diseases - bronchial asthma and COPD, older 30 years. The diagnosis asthma and COPD was set by criteria, presented in GINA and GOLD $[17,18]$. The patients' condition was stable, exacerbations were absent for 2 months before the beginning of the study.

The association of asthma and COPD was proved by the results of the study of the external breath function $(\mathrm{EBF})$ - in all patients was detected the fixed disorder of the respiratory tracts permeability - ratio of a forced exhalation volume for the first second/ force vital capacity of lungs (FEV1/FVC) $<70 \%$ after a bronchodilator (conventional COPD marker) and the reverse character of bronchial obstruction - FEV1 increment by $\geq 12 \%$ and $\geq 200 \mathrm{ml}$ after using a bronchodilator (400 mcg of salbutamol), is usually more inherent to the bronchial asthma.

The study included patients with the bronchial asthma and COPD without pathologies association signs as a control.

Patients underwent the standard basic therapy of BA and COPD according to the disease severity degree, all took $\beta 2$-agonists of a short action (STBA) at the necessity and preparations for the disease control: (inhalation corticosteroids ICS), combination ICS $+\beta 2$-antagonists of a long action (LABA), tiotropium bromide or the triple therapy - ICS/LABA, tiotropium bromide.

Characteristic of patients is presented in Table $\mathbf{1 .}$

Table 1

Characteristic of patients

\begin{tabular}{|c|c|c|c|}
\hline Parameters & BA $(n=34)$ & COPD $(n=17)$ & $B A+C O P D(n=140)$ \\
\hline Sex, $n$ & 27 women, 7 men & 7 women, 10 men & 74 women, 66 men \\
\hline Age, years & $50,76 \pm 1,5$ & $67,36 \pm 2,27$ & $58,56 \pm 0,81$ \\
\hline Body mass index, $\mathrm{kg} / \mathrm{m}^{2}$ & $31,64 \pm 1,39$ & $30,02 \pm 1,46$ & $28,82 \pm 0,43$ \\
\hline Smoking period pack/years & $2,87 \pm 1,28$ & $8,06 \pm 3,28$ & $10,35 \pm 1,77$ \\
\hline Ex-smokers, \% & 12 & 18 & 7 \\
\hline Smokers, \% & 20 & 29 & 34 \\
\hline Never smoked, $\%$ & 68 & 53 & 59 \\
\hline \multicolumn{4}{|l|}{ BA severity degree } \\
\hline light, $\%$ & 32 & & 6 \\
\hline Middle severity, \% & 59 & & 79 \\
\hline severe, $\%$ & 9 & & 15 \\
\hline \multicolumn{4}{|l|}{ Groups of patients with COPD } \\
\hline $\mathrm{A}, \%$ & & 18 & 13 \\
\hline $\mathrm{B}, \%$ & & 11 & 21 \\
\hline C, \% & & 18 & 20 \\
\hline $\mathrm{D}, \%$ & & 53 & 46 \\
\hline \multicolumn{4}{|l|}{$\begin{array}{l}\text { Bronchial obstruction severity degree } \\
\text { GOLD }\end{array}$} \\
\hline $1, \%$ & & 29 & 29 \\
\hline $2, \%$ & & 29 & 58 \\
\hline $3, \%$ & & 36 & 11 \\
\hline $4, \%$ & & 6 & 2 \\
\hline \multicolumn{4}{|l|}{ Therapy before inclusion in the study } \\
\hline SABA, if necessary, $\%$ & 100 & 100 & 100 \\
\hline ICS, \% & 15 & 12 & 6 \\
\hline $\mathrm{ICS} / \mathrm{LABA}, \%$ & 85 & 88 & 89 \\
\hline Tiotropium bromide, $\%$ & 0 & 12 & 3 \\
\hline ICS/LABA, tiotropium bromide, $\%$ & 0 & 0 & 2 \\
\hline
\end{tabular}


For determining the presence and severity degree of the bronchial obstruction, all patients underwent the spirometry with the analysis of the curve "flow-volume" of a forced exhalation and also the bodypletizmography on the set for the respiratory system study "MasterScreenPneumo", 2007, made by "CardinalHealth" (Germany).

All patients were interrogated by the questionnaires: BA symptoms control questionnaire (ACQ-7), BA control test (ACT), COPD assessment test (CAT).

The accumulation of data and their mathematical processing were realized using licensed program products, included in the package Microsoft Office Professional 2007, license RussianAcademic OPEN NoLevel No. 43437596. The statistical processing was realized using mathematical and statistical possibilities of MS Excel, and also additional statistical function, elaborated by S. N. Lapach, A. V. Chubenko, P. N. Babych [19]. The parameters, investigated in the study, were assessed using the determination of the mean value $(\mathrm{M})$, mistake of the mean value $(\mathrm{m})$, reliability criterion $(\mathrm{t})$, importance level $(\mathrm{p})$, with the further comparison using Student t-criterion and Mann-Whitney U-criterion depending on the distribution type of received data. The checking of numerical lines for the correspondence to the normal distribution was realized using the special NORMSAMP_1 functions, developed for Excel program [19].

\section{Results}

At comparing parameters of BA control was revealed the reliably worse control in the group of patients with the associated pathology by data of the questionnaire ACQ-7 comparing with patients with BA. The influence of COPD symptoms was also more essential in patients with ACC comparing with ones with COPD.

So, the association of two nosologies had a negative influence on both BA control degree and COPD symptoms expressiveness. The data are presented on Fig. 1, 2.

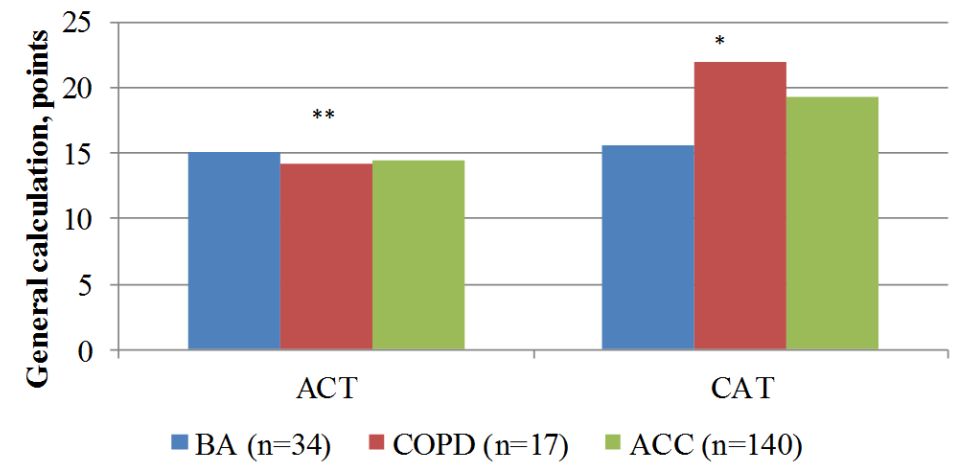

Fig. 1. General calculation of ACT and CAT in studied patients:

$*-\mathrm{p}<0,05 ; * *-\mathrm{p}<0,01$ comparing with BA

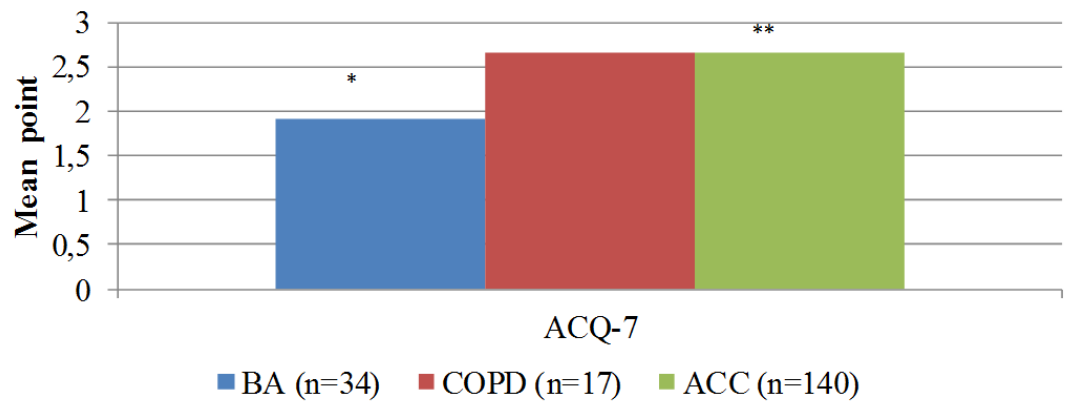

Fig. 2. General calculation of ACQ-7 in studied patients:

$*-\mathrm{p}<0,05 ; * *-\mathrm{p}<0,01$ comparing with BA

There was also analyzed, what part of patients from BA and ACC groups had BA control and of what degree (Fig. 3, 4). 


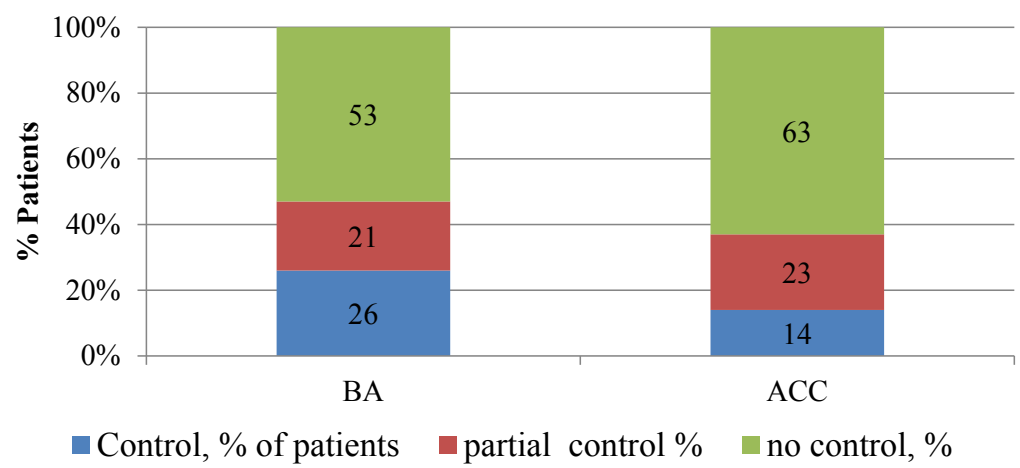

Fig 3. Distribution of patients with BA and ACC by BA control level according to ACT

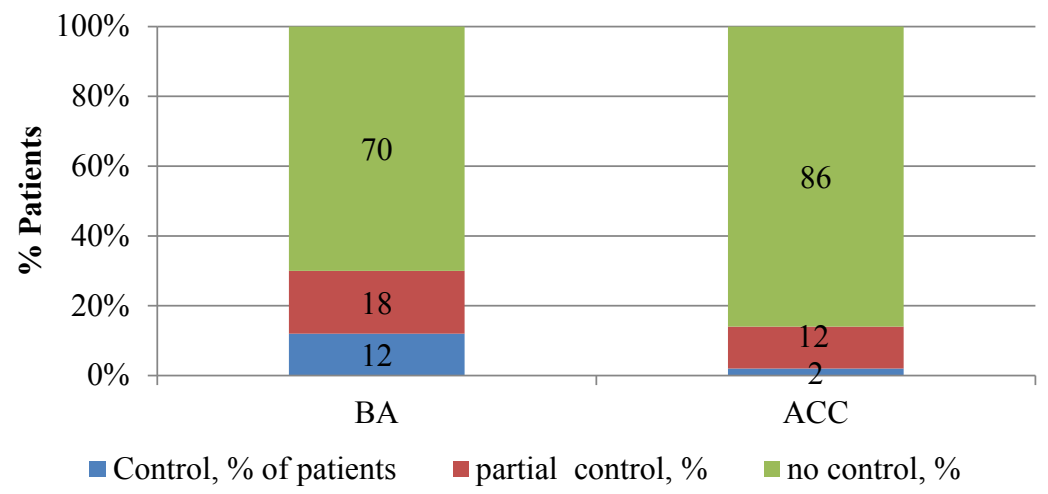

Fig. 4. Distribution of patients with BA and ACC by BA control level according to ACQ-7

The part of patients with ACC, in whom the good asthma control was detected by both ACT and ACQ-7 results, is essentially less than at the single BA (ACT $\geq 20$ points was in $14 \%$ of patients with ACC against $26 \%$ - at BA without an association and ACQ-7 $\geq 1,5$ points - in $2 \%$ against $12 \%$ ).

It testifies to the essential contribution of the concomitant COPD in the weaker BA control in patients with the associated pathology. A doctor-practician must assess the condition and symptoms of the disease more accurately especially at such co-morbid pathology, start the rational therapy as early as possible, because it is well-known, that it may essentially influence the disease prognosis.

There was also analyzed the influence of COPD symptoms on the condition of patients with ACC and COPD. The moderate and essential influence was revealed in $88 \%$ of patients with COPD and in $93 \%$ of patients with the associated pathology. The data are demonstrated on Fig. 5.

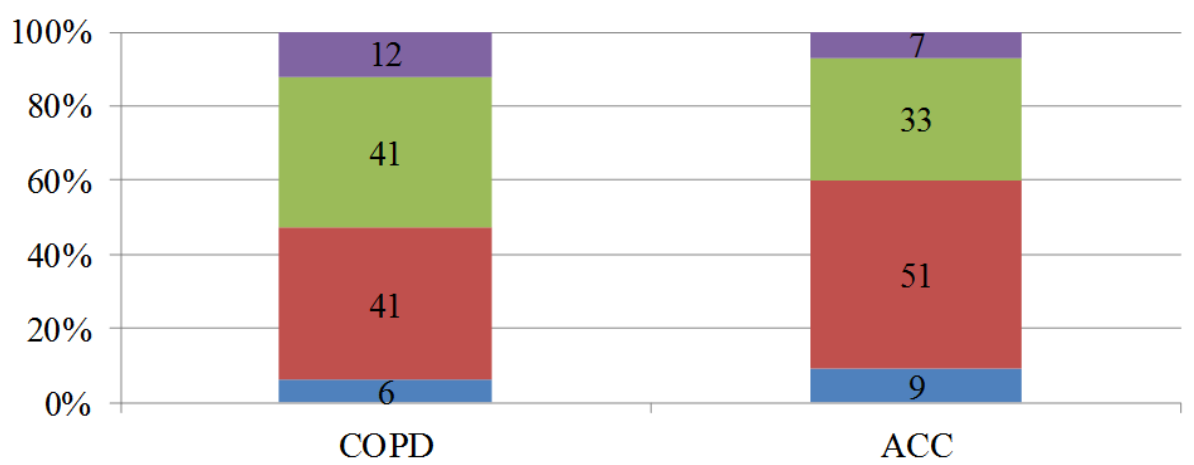

- light, \% $\quad$ moderate, $\% \quad$ severe, $\% \quad$ v very severe, $\%$

Fig. 5. Distribution by COPD influence degree on patients' life 
The following task of the study was the determination of the control level and influence of BA and COPD association on the condition of patients' with the associated pathology depending on the bronchial obstruction severity degree.

The distribution of patients by the degree of the bronchial obstruction intensity was realized according to the spirometric classification of GOLD (Table 2) [17].

Table 2

Classification of the bronchial obstruction severity at COPD by FEV 1 level after taking a broncholytic (GOLD, 2017)

\begin{tabular}{cc}
\hline Degree & FEV $_{\mathbf{1}}$ indices, \% of proper ones \\
\hline GOLD 1 (light) & $\mathrm{FEV}_{1} \geq 80 \%$ \\
GOLD 2 (moderate) & $50 \leq \mathrm{FEV}_{1}<80 \%$ \\
GOLD 3 (severe) & $30 \leq \mathrm{FEV}_{1}<50 \%$ \\
GOLD 4 (vey severe) & $\mathrm{FEV}_{1}<30 \%$
\end{tabular}

Because the group GOLD 4 included only 2 patients, groups 3 and 4 were combined for the data analysis. At the more expressed bronchial obstruction degree BA control was reliably weaker, whereas an influence of COPD symptoms more essential.

The indices of the control and disease influence on the life of patients with ACC depending on the bronchial obstruction degree are presented on Fig. 6, 7.

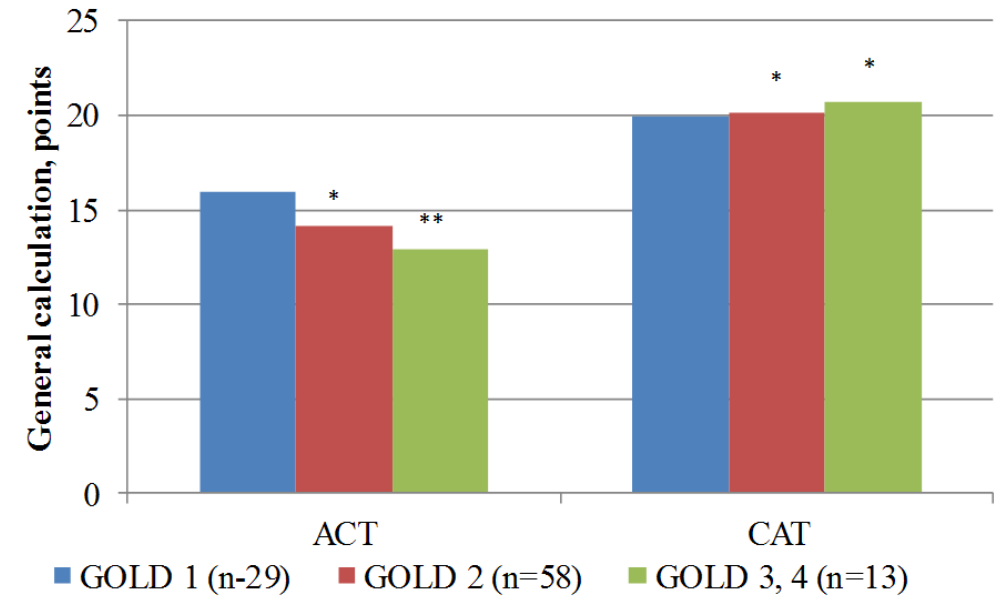

Fig. 6. Control degree and intensity of symptoms (ACT and CAT) of patients with ACC comparing with the bronchial destruction degree: * ${ }^{*} \mathrm{p}<0,05$; ** $-\mathrm{p}<0,01$ comparing with GOLD 1

For assessing the patients' condition and prognosticating risk of death from any case and from the pulmonary pathology in patients with the bronchial pulmonary pathology, BODE index is widely used in the world: it is a multiparametric system of point assessment of a condition of a patient with COPD [20, 21].

For assessing the risk of a worse prognosis in patients with BA+COPD using BODE index determination ( $\mathrm{BODE} \geq 2$ ), the chance ratio was calculated in patients with the severe and very severe COPD degree (CAT $\geq 20$ points). The index of the chance ratio was 2,39 and had $95 \%$ reliable interval within $1,13-5,08(p<0,05)$. It testifies to the fact that in patients with CAT index $\geq 20$, the mortality prognosis, expressed by BODE index, grows more than twice. So, there is demonstrated 
the high connection of COPD symptoms and disease prognosis in patients with the associated pathology BA+COPD.

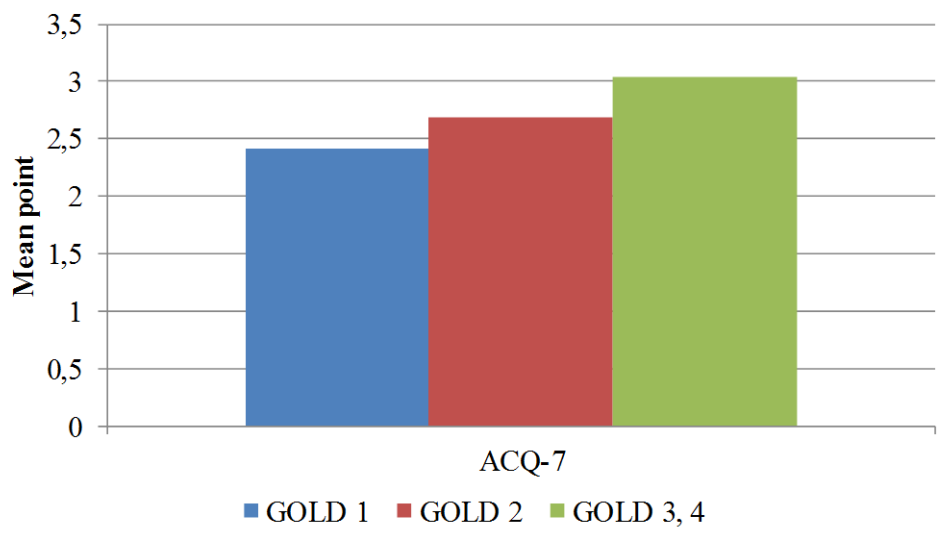

Fig. 7. Control degree (ACQ) of patients with ACC depending of the bronchial destruction level: $*-\mathrm{p}<0,05 ; * *-\mathrm{p}<0,01$ comparing with GOLD 1

At assessing the worse prognosis of COPD in patients with BA+COPD and the unsatisfactory BA (ACT $<20$ points), the change ratio index was 2,72 and had $95 \%$ reliable interval within 1,04 to $7,14(\mathrm{p}<0,05)$. It testifies to the fact that in patients with ACC with the low BA control, the mortality prognosis, expressed by BODE index grows more than in 2,5 times. After using ACQ-7 questionnaire (bad control $\geq 1,5$ points) - the chance ratio was 2,96 at the $95 \%$ reliable interval within 1,11 to $7,94(\mathrm{p}<0,05)$. That is in patients with the unsatisfactory BA control, according to ACQ-7, the mortality prognosis by BODE index grows almost in 3 times.

Thus, there was revealed the essential negative influence of the insufficient BA control and strong influence of COPD symptoms on the disease prognosis in patients with the associated pathology BA+COPD.

The symptoms severity and limitation of everyday activity of patients with the bronchial obstructive pathology are conditioned by the inability to breathe fully. Asthma and COPD are usually attended with EBF changes, manifested by the respiratory tracts permeability disorder, hyperactivity of respiratory tracts at COPD, and at the long clinical course of asthma - by the fixed bronchial obstruction, signs of pulmonary hyperinflation and so on [22, 23].

The correlative analysis between the indices of COPD influence on the condition of patients with ACC (by CAT) and EBF was realized.

The reliable positive correlation was revealed between the point by CAT and ratio of the internal thoracic gases volume to the general lung capacity (ITGV/TLC), that reflects the degree of lungs hyperinflation $-(r=0,35 ; \mathrm{p}<0,05)$ (Fig. 8).

\section{Interaction of CAT test index and} ITGV/TLC

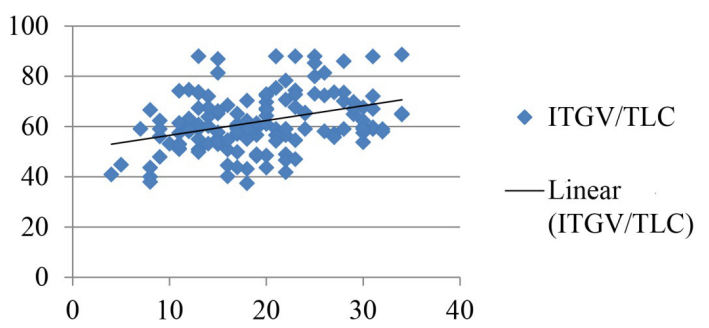

Fig. 8. The correlative analysis of CAT point and EBF indices

It proves the fact that the more COPD influence degree on the condition of patients with $\mathrm{ACC}$, the more expressed hyperinflation signs of these patients are. 


\section{Discussion}

There is an essential layer of data about the influence of COPD symptoms, bad BA control on the prognosis, life quality of patients with BA and COPD. But for today there is not enough data in the literature about the role of the severity and control of the disease at the associated bronchial obstructive pathology.

At this study the combination of two nosologies had a negative influence on both BA control degree and COPD symptoms intensity. Both the disease control and symptoms intensity degree were more expressed just in patients with the associated bronchial obstructive pathology.

At the analysis of data of the questionnaires of patients with ACC depending on the bronchial destruction level, the data were received about the reliably weaker control and essential influence of COPD symptoms in patients with the more disease severity level.

Using the assessment by BODE index, there was demonstrated the close connection between the CAT point and negative prognosis at the associated bronchial obstructive pathology. The disease prognosis essenrially depended on the BA control degree.

The received data allow to make an accent on the other important presupposition in the BA control in patients with the associated bronchial obstructive pathology, attended by the strong influence of COPD symptoms on patients' everyday life and also by the reliably worse disease prognosis. In the clinical practice such patients must be supervised taking into account these important features of this pathological state.

\section{Conclusions}

1. At the BA and COPD association, indices of the diseases control are worse than at the bronchial asthma and a bit similar to ones at COPD.

2. The indices of the BA control, COPD symptoms influence on the condition of patients with the associated bronchial obstructive pathology were mainly negatively changed at the increase of the bronchial obstruction degree.

3. In patients with $\mathrm{ACC}$ with the unsatisfactory $\mathrm{BA}$ control (ACQ-7 $\geq 1,5$ points) the mortality prognosis, expressed by BODE index, grows more than in 3 times; in patients with the severe and very severe influence of the disease effect (CAT $>20$ points), the mortality prognosis increases more than twice.

4. The special attention must be paid just to patients with the associated bronchial obstructive pathology to prevent complications and improve the disease prognosis; the other important task in the treatment of the associated bronchial obstructive pathology is an attainment of BA and timely and complete therapy for decreasing symptoms and risk factors of undesirable results of both pathological states.

\section{References}

[1] Feschenko, Y. (2015). Bronhialna astma, hronichne obstruktivne zahvoryuvannya legen: perspektivna globalna strategiya vedennya, novitni metodi diagnostiki, suchasni pidhodi do terapiyi. Astma ta alergiya, 4, 38-42.

[2] Postma, D. S., Rabe, K. F. (2015). The Asthma-COPD Overlap Syndrome. New England Journal of Medicine, 373 (13), 1241-1249. doi: 10.1056/nejmra1411863

[3] Accordini, S., Corsico, A. G., Braggion, M., Gerbase, M. W., Gislason, D., Gulsvik, A. et. al. (2013). The Cost of Persistent Asthma in Europe: An International Population-Based Study in Adults. International Archives of Allergy and Immunology, 160 (1), 93-101. doi: 10.1159/000338998

[4] Bateman, E. D., Reddel, H. K., Eriksson, G., Peterson, S., Ostlund, O., Sears, M. R. et. al. (2010). Overall asthma control: The relationship between current control and future risk. Journal of Allergy and Clinical Immunology, 125 (3), 600-608. doi: 10.1016/j.jaci.2009.11.033

[5] Guilbert, T. W., Garris, C., Jhingran, P., Bonafede, M., Tomaszewski, K. J., Bonus, T. et. al. (2010). Asthma That Is Not Well-Controlled Is Associated with Increased Healthcare Utilization and Decreased Quality of Life. Journal of Asthma, 48 (2), 126-132. doi: 10.3109/02770903.2010.535879 
[6] Doz, M., Chouaid, C., Com-Ruelle, L., Calvo, E., Brosa, M., Robert, J. et. al. (2013). The association between asthma control, health care costs, and quality of life in France and Spain. BMC Pulmonary Medicine, 13 (1), 15-16. doi: 10.1186/1471-2466-13-15

[7] Schatz, M., Sorkness, C. A., Li, J. T., Marcus, P., Murray, J. J., Nathan, R. A. et. al. (2006). Asthma Control Test: Reliability, validity, and responsiveness in patients not previously followed by asthma specialists. Journal of Allergy and Clinical Immunology, 117 (3), 549-556. doi: 10.1016/j.jaci.2006.01.011

[8] Nathan, R. A., Sorkness, C. A., Kosinski, M., Schatz, M., Li, J. T., Marcus, P. et. al. (2004). Development of the asthma control test A survey for assessing asthma control. Journal of Allergy and Clinical Immunology, 113 (1), 59-65. doi: 10.1016/j.jaci.2003.09.008

[9] Juniper, E. F., O'byrne, P. M., Guyatt, G., Ferrie, P., King, D. (1999). Development and validation of a questionnaire to measure asthma control. European Respiratory Journal, 14 (4), 902-907. doi: 10.1034/j.1399-3003.1999.14d29.x

[10] Unifikovaniy klinichniy protokol pervinnoyi, vtorinnoyi (spetsializovanoyi) medichnoyi dopomogi «Bronhialna astma»(2013). MOZ Ukrayini, No. 868.

[11] Wyrwich, K. W., Khan, S. A., Navaratnam, P., Nolte, H., Gates, D. F. (2011). Validation and agreement across four versions of the asthma control questionnaire in patients with persistent asthma. Respiratory Medicine, 105 (5), 698-712. doi: 10.1016/j.rmed.2010.11.004

[12] Juniper, E. F., Svensson, K., Mork, A.-C., Stahl, E. (2005). Measurement properties and interpretation of three shortened versions of the asthma control questionnaire. Respiratory Medicine, 99 (5), 553-558. doi: 10.1016/j.rmed.2004.10.008

[13] Svensson, K., Mork, A., Juniper, E. (2003). ACQ-is five out of seven items acceptable in large clinical studies? Quality of Life Research, 12, 771-772.

[14] Unifikovaniy klnichniy protokol pervinnoyi (vtorinnoyi) spetsializovanoyi, tretinnoyi (visokospetsializovanoyi) medichnoyi dopomogi ta medichnoyi reabilitatsiyi «Hronichne obstruktivne zahvoryuvannya legeni» (2013). MOZ Ukrayini, No. 555. «Pro zatverdzhennya standartizatsiyi medichnoyi dopomogi pri HOZL»

[15] Jones, P. W., Harding, G., Berry, P., Wiklund, I., Chen, W.-H., Kline Leidy, N. (2009). Development and first validation of the COPD Assessment Test. European Respiratory Journal, 34 (3), 648-654. doi: 10.1183/09031936.00102509

[16] Ringbaek, T., Martinez, G., Lange, P. (2012). A Comparison of the Assessment of Quality of Life with CAT, CCQ, and SGRQ in COPD Patients Participating in Pulmonary Rehabilitation. COPD: Journal of Chronic Obstructive Pulmonary Disease, 9 (1), 12-15. doi: 10.3109/15412555.2011.630248

[17] The Global Initiative for Chronic Obstructive Lung Disease (GOLD) (2017). Available at: http:// goldcopd.org/wp-content/uploads/2016/12/wms-GOLD-2017-Pocket-Guide.pdf

[18] Global Initiative for Asthma - GINA (2017). Available at: http://ginasthma.org/

[19] Lapach, S., Chubenko, A., Babich, P. (2000). Statisticheskie metodyi v mediko-biologicheskih issledovaniyah s ispolzovaniem Excel. Kyiv: Morion, 320.

[20] Cote, C. G. (2005). Pulmonary rehabilitation and the BODE index in COPD. European Respiratory Journal, 26 (4), 630-636. doi: 10.1183/09031936.05.00045505

[21] Celli, B. R., Cote, C. G., Marin, J. M., Casanova, C., Montes de Oca, M., Mendez, R. A. et. al. (2004). The Body-Mass Index, Airflow Obstruction, Dyspnea, and Exercise Capacity Index in Chronic Obstructive Pulmonary Disease. New England Journal of Medicine, 350 (10), 1005-1012. doi: 10.1056/nejmoa021322

[22] Deesomchok, A., Webb, K. A., Forkert, L., Lam, Y.-M., Ofir, D., Jensen, D., O’Donnell, D. E. (2010). Lung Hyperinflation and Its Reversibility in Patients with Airway Obstruction of Varying Severity. COPD: Journal of Chronic Obstructive Pulmonary Disease, 7 (6), 428-437. doi: 10.3109/15412555.2010.528087

[23] O’Donnell, D. E., Laveneziana, P., Webb, K., Neder, J. A. (2014). Chronic Obstructive Pulmonary Disease. Clinics in Chest Medicine, 35 (1), 51-69. doi: 10.1016/j.ccm.2013.09.008 